Article

\title{
Applying Biotechnology in the Propagation and Further Selection of Vaccinium uliginosum $\times$ (V. corymbosum $\times V$. angustifolium) Hybrids
}

\author{
Anna A. Erst ${ }^{1, *}$, Aleksey B. Gorbunov ${ }^{1}$, Sergey V. Asbaganov ${ }^{1}\left(\mathbb{D}\right.$, Maria A. Tomoshevich ${ }^{1}$, Evgeny V. Banaev ${ }^{1}$ \\ and Andrey S. Erst ${ }^{1,2}$ \\ 1 Central Siberian Botanical Garden of the Siberian Branch of the Russian Academy of Sciences, \\ 630090 Novosibirsk, Russia; gab_2002ru@ngs.ru (A.B.G.); cryonus@mail.ru (S.V.A.); arysa9@mail.ru (M.A.T.); \\ alnus2005@mail.ru (E.V.B.); erst_andrew@yahoo.com (A.S.E.) \\ 2 Laboratory of Herbarium, National Research Tomsk State University, 634050 Tomsk, Russia \\ * Correspondence: erst_aa@csbg-nsk.ru; Tel.: +7-383-330-41-01
}

check for updates

Citation: Erst, A.A.; Gorbunov, A.B.; Asbaganov, S.V.; Tomoshevich, M.A.; Banaev, E.V.; Erst, A.S. Applying Biotechnology in the Propagation and Further Selection of Vaccinium uliginosum $\times(V$. corymbosum $\times V$. angustifolium) Hybrids. Plants 2021, 10, 1831. https://doi.org/10.3390/ plants10091831

Academic Editors: Shri Mohan Jain and Jameel M. Al-Khayri

Received: 2 August 2021

Accepted: 2 September 2021

Published: 3 September 2021

Publisher's Note: MDPI stays neutral with regard to jurisdictional claims in published maps and institutional affiliations.

Copyright: (c) 2021 by the authors. Licensee MDPI, Basel, Switzerland. This article is an open access article distributed under the terms and conditions of the Creative Commons Attribution (CC BY) license (https:/ / creativecommons.org/licenses/by/ $4.0 /)$.

\begin{abstract}
The most serious problem of intergeneric and interspecific hybridization is related to overcoming the reproductive isolation of different species. We assessed the efficiency of reproduction under in vitro conditions and the ex vitro growth capacity of interspecific hybrids of Vaccinium uliginosum $\times(V$. corymbosum $\times V$. angustifolium $)$. The percentage of seed germination in in vitro culture was $88 \%$ for $V$. uliginosum, form No. $8 \times(V$. corymbosum $\times V$. angustifolium $)$, SC5-8, while it was $42 \%$ for $V$. uliginosum, form No. $8 \times($. corymbosum $\times V$. angustifolium $)$, 'Northcountry'. The analysis of mean value showed that the multiplication rate increased and the shoot height decreased as the 2-isopentenyl adenine (2iP) concentration was increased in the nutrient medium of the studied hybrids. The maximum rate was achieved using $15 \mu \mathrm{M} 2 \mathrm{iP}$. A detailed analysis of the hybrids indicated that the hybrid variant reliably affected growth and development indicators. Inter simple sequence repeat analysis demonstrated that all analyzed hybrids inherited DNA fragments of the parent plants in various combinations, confirming their hybrid nature. Thus, the use of in vitro methods for the propagation and further selection of genotypes is demonstrated as being an effective approach for developing interspecific hybrids of $V$. uliginosum $\times($. corymbosum $\times V$. angustifolium $)$.
\end{abstract}

Keywords: interspecific hybrids; berry crops; in vitro culture; ISSR analysis

\section{Introduction}

A promising area of blueberry breeding in Siberia is interspecific hybridization involving the most productive resistant varieties and selected forms of half-highbush blueberry (Vaccinium corymbosum $\times V$. angustifolium, $2 \mathrm{n}=48$ ) and a local species of bog blueberry (V. uliginosum L., $2 \mathrm{n}=48$ ). However, the most serious problem of intergeneric and interspecific hybridization is related to overcoming the reproductive barrier that separates species. The use of in vitro techniques makes it possible to obtain viable hybrids from seeds that have an underdeveloped embryo and to overcome the negative effect of various factors on seed germination and seedling viability at the initial stages of development. In vitro embryo culture can be used to overcome the barriers of nonbreeding in interspecific hybridization of Vaccinium species with different levels of ploidy [1]. Furthermore, when treated with colchicine, in vitro culture allows for amphiploid hybrids to be obtained by crossing species of different ploidy, such as $V$. corymbosum $\times V$. ashei [2].

Rousi [3] provided the first evidence that amphidiploidy could be useful in breeding blueberries suitable for less favorable areas of cultivation. The report detailed obtaining viable fertile hybrids of the tetraploids of V. uliginosum (section Vaccinium) and V. corymbosum L. (section Cyanococcus). Similar interspecific hybrids were obtained in Poland, Russia, and other countries [4-6], and in Japan using the wild-growing hexaploid race $V$. uliginosum $(2 \mathrm{n}=6 \mathrm{x}=72)$, and $V$. corymbosum 'Bluecrop' [7]. These researchers found that seeds 
were easier to obtain when applying $V$. uliginosum as a seed parent in comparison with parental pollen, and unilateral cross incompatibility occurred in reciprocal crosses. The resulting hybrid seeds germinated after pretreatment with gibberellin in in vitro culture or in nurseries after stratification [7]. While developing mononuclear tetrads of microspores into mature binuclear pollen grains, Luzyanina [8] revealed a higher amount of defective pollen from $V$. uliginosum, which determined the low pollen quality. Therefore, this species is best used as a maternal plant. Earlier, it was shown that tetraploid bog blueberry (from a population in Novosibirsk region, Russia) easily crosses with tetraploid high blueberry and half-high blueberry (fruit set was 70.6 and 50.0\%, respectively) [9]. In interspecific breeding programs, a relatively large number of hybrids are needed to be able to identify adequate genetic variation in the participating species and to avoid inbreeding depression in advanced generations [10].

This research was carried out to assess the possibility of using in vitro techniques to propagate interspecific hybrids of $V$. uliginosum $\times(V$. corymbosum $\times V$. angustifolium $)$ since previous studies have not examined the in vitro culture of seeds of these hybrids.

\section{Results}

The seed germination percentage of hybrids in in vitro culture was $42 \%$ for $V$. uliginosum, form No. $8 \times($ V. corymbosum $\times V$. angustifolium), 'Northcountry' (V.ul.8 $\times$ 'NC') and $88 \%$ for $V$. uliginosum, form No. $8 \times(V$. corymbosum $\times V$. angustifolium), 'SC 5-8' $\left(\right.$ V.ul.8 $\times$ 'SC 5-8') (Table 1 and Figure 1a). In total, we received 19 seedlings of V.ul.8 $\times$ ' $\mathrm{NC}^{\prime}$ and 22 seedlings (variants) of V.ul.8 $\times$ 'SC 5-8'. The germination rate of seeds in the soil substrate was $80 \%$, and the survival rate was no more than $2 \%$. A comparison of plants obtained in vitro and sown in soil was not carried out due to the unrepresentative sample of the latter. The experimental scheme is shown in Figure 2. As a result, the research showed that 11 variants $(78 \%)$ of V.ul.8 $\times{ }^{\prime} \mathrm{NC}^{\prime}$ and 7 variants (32\%) of V.ul.8 $\times$ 'SC 5-8' were capable of morphogenesis (shoot formation) in in vitro culture. Significant differences in the multiplication rate among the studied hybrid variants were noted at the second passage. As for the hybrid of V.ul.8 $\times$ ' $\mathrm{NC}^{\prime}$, its maximum and minimum multiplication rates were 42.5 shoots/explant for variants No. 4-5 and 1.3 shoots/explant for No. 4-1 (Figures $1 b, c$ and 3a). The maximum multiplication factor of the hybrid of V.ul.8 × 'SC 5-8' was observed in variant No. 7-12 and amounted to 19 shoots/explant, while the minimum was 2.8 shoots/explant in variant No. 7-7. Callus formation was only observed in variant No. 7-11 (Figure 3b). Further research showed that not all variants of the studied hybrids were capable of long-term in vitro cultivation on Anderson nutrient medium supplemented with $5 \mu \mathrm{M}$ 2-isopentenyl adenine (2iP). Some variants died, while others formed a callus and were excluded from subsequent experiments.

Table 1. The number of pollinated flowers, set fruits, seeds, and the percentage of germination of Vaccinium uliginosum $\times$ (V. corymbosum $\times V$. angustifolium) hybrids on $0.6 \%$ water agar in in vitro culture.

\begin{tabular}{|c|c|c|c|c|c|}
\hline Hybrid & $\begin{array}{l}\text { Pollination } \\
\text { Bag }\end{array}$ & $\begin{array}{l}\text { No. of Pollinated } \\
\text { Flowers }\end{array}$ & $\begin{array}{l}\text { No. of Fruits/ } \\
\text { Seeds }\end{array}$ & $\begin{array}{l}\text { No. of Seedlings } / \% \text { of } \\
\text { Germination }\end{array}$ & $\begin{array}{c}\text { Variant } \\
\text { Abbreviations }\end{array}$ \\
\hline V.ul.8 $\times{ }^{\prime} \mathrm{NC}^{\prime}$ & 1 & 22 & $3 / 17$ & $5 / 29$ & No. $1-1 \ldots$ No. $1-5$ \\
\hline V.ul. $8 \times{ }^{\prime} \mathrm{NC}^{\prime}$ & 2 & 22 & $1 / 8$ & $2 / 25$ & No. 2-1, No. 2-2 \\
\hline V.ul.8 $\times{ }^{\prime} \mathrm{NC}^{\prime}$ & 3 & 11 & $1 / 3$ & $0 / 0$ & - \\
\hline V.ul. $8 \times{ }^{\prime} \mathrm{NC}^{\prime}$ & 4 & 10 & $4 / 17$ & $8 / 47$ & No. $4-1 \ldots$ No. $4-8$ \\
\hline V.ul. $8 \times{ }^{\prime} \mathrm{NC}^{\prime}$ & 5 & 6 & $2 / 4$ & $4 / 100$ & No. $5-1 \ldots$ No. $5-4$ \\
\hline V.ul. $8 \times$ 'SC 5-8' & 6 & 20 & $4 / 6$ & $6 / 100$ & No. 6-1 ... No. 6-6 \\
\hline V.ul.8 × 'SC 5-8' & 7 & 18 & $5 / 19$ & $16 / 84$ & $\begin{array}{c}\text { No. } 7-1 \ldots \text { No. } \\
7-16\end{array}$ \\
\hline
\end{tabular}




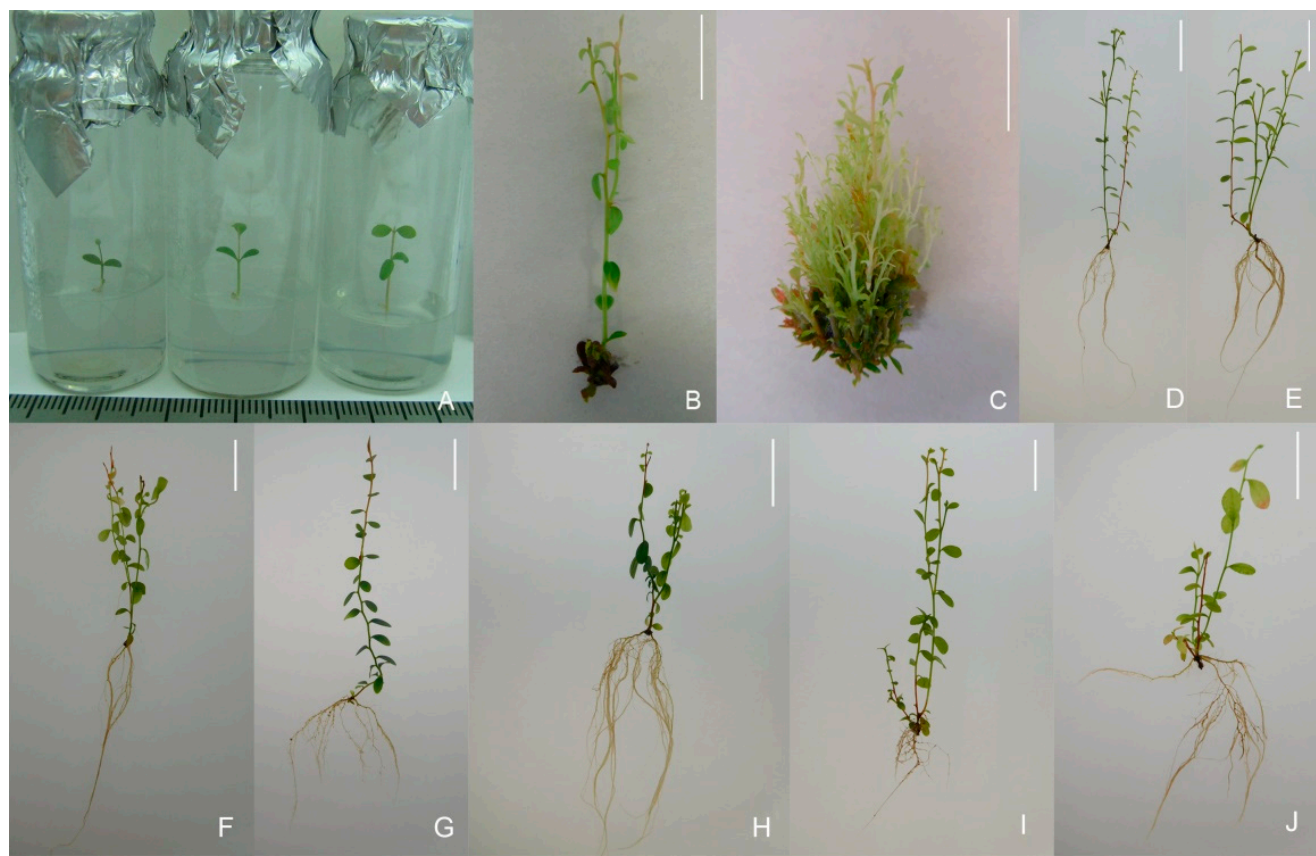

Figure 1. V. uliginosum $\times($ V. corymbosum $\times$ V. angustifolium $)$ hybrids in in vitro culture: (A) seedlings on $0.6 \%$ water agar; $(B, C)$ microshoots of variant No. $4-1$ and variant No. $4-5$ on Anderson medium, supplemented $5 \mu \mathrm{M}$ 2iP; (D-J) rooted plants of variant Nos. 1-1, 1-2, 1-5, 2-2, 4-2, 4-8, 7-9 on 1/2 Anderson medium. Bar: $1 \mathrm{~cm}$.

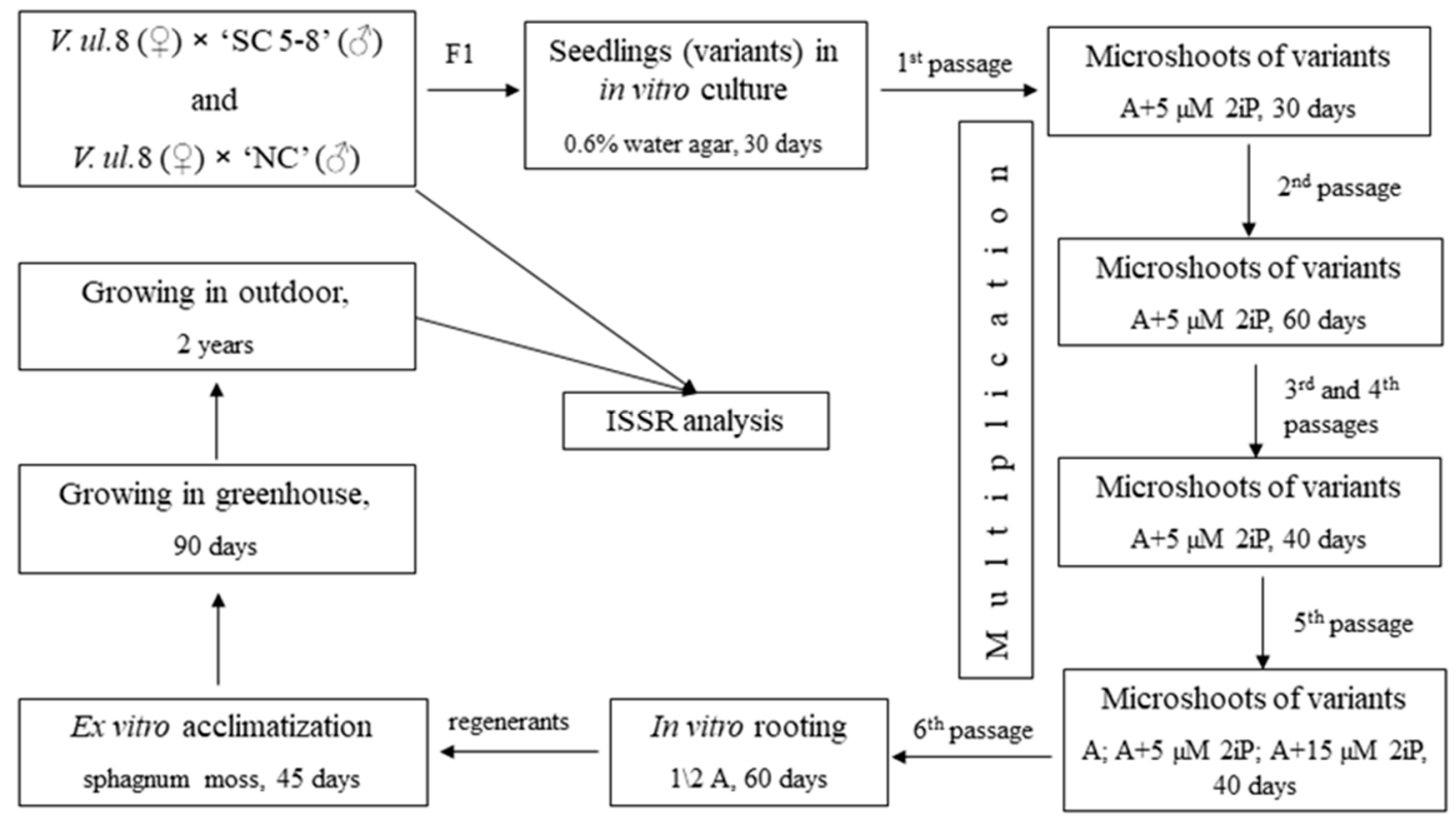

Figure 2. Schematic depiction of the experiment showing stages of in vitro propagation and ex vitro acclimatization, conditions and cultivation periods. Note: V.ul.8-V. uliginosum, form No. 8; 'NC'-(V. corymbosum $\times$ V. angustifolium) 'Northcountry'; 'SC 5-8'-(V. corymbosum $\times$ V. angustifolium $)$ 'SC 5-8'; A-Anderson nutrient medium.

The analysis of the average multiplication rate values showed that this parameter increased along with the 2iP concentration in the nutrient medium (Figures 4 and $5 p \leq 0.05$ ) for hybrids of V.ul.8 $\times$ ' $\mathrm{NC}$ ' and V.ul.8 $\times$ 'SC 5-8'. A detailed analysis of this parameter for variant No. 6-3 showed no notable differences in the multiplication rate in all tested media modifications. However, other variants showed reliable differences when using $15 \mu \mathrm{M} 2 \mathrm{iP}$. Among the variants of V.ul.8 $\times$ 'SC 5-8', the differences among the experimental variants 
were demonstrated to be insignificant $(p \leq 0.05)$ for variant No. 7-9. However, significant differences from the control were shown only on media with $15 \mu \mathrm{M}$ cytokinin for variant No. 7-3; hybrid No. 6-2 was characterized by a considerable increase in the multiplication rate as the $2 \mathrm{iP}$ concentration increased. The highest multiplication rate was obtained with the nutrient medium to which $15 \mu \mathrm{M} 2 \mathrm{iP}$ was added, which had a multiplication rate of 8.9 shoots/explant for variant No. 1-2 of the V.ul.8 $\times$ ' $\mathrm{NC}^{\prime}$ and 3.4 shoots/explant for variant No. 6-2 of V.ul.8 × 'SC 5-8'. Variant No. 4-6 formed only a conglomerate of shoots in this medium. The factor analysis confirmed that both the 2iP concentration and the variant of hybrid influenced the multiplication rate of the studied hybrids (Table 2).

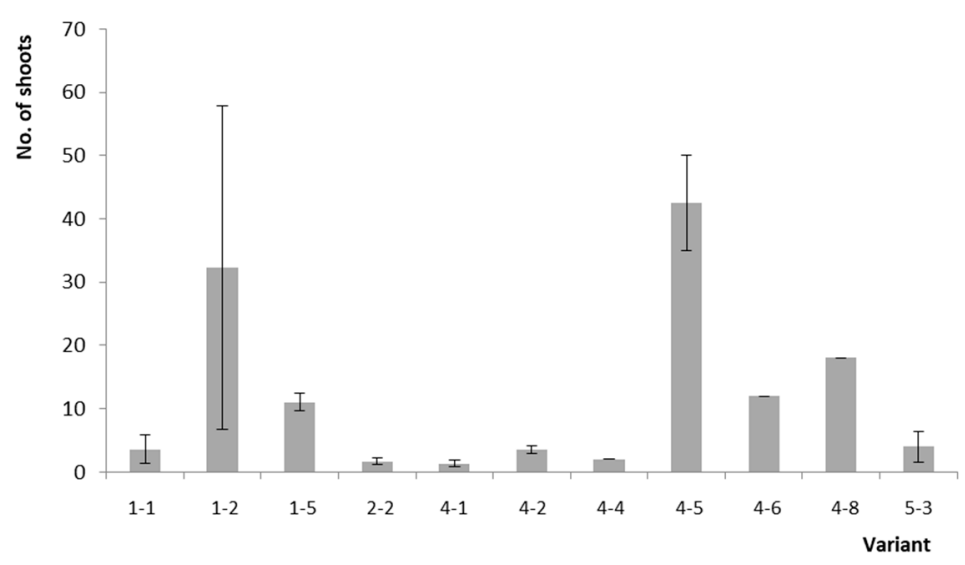

(A)

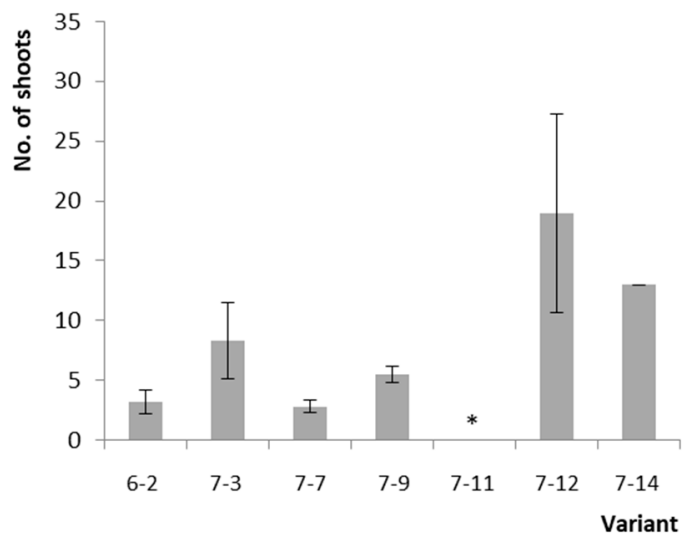

(B)

Figure 3. The multiplication rate of variants $V . u l .8 \times{ }^{\prime} \mathrm{NC}^{\prime}(\mathbf{A})$ and $V . u l .8 \times$ 'SC 5-8' (B) on Anderson medium, supplemented $5 \mu \mathrm{M} 2 \mathrm{iP}$ at the 2 nd passage. Data are presented as mean values with confidence intervals $(p \leq 0.05)$. N = 1-6. Note: *-callusogenesis of variant No. 7-11.

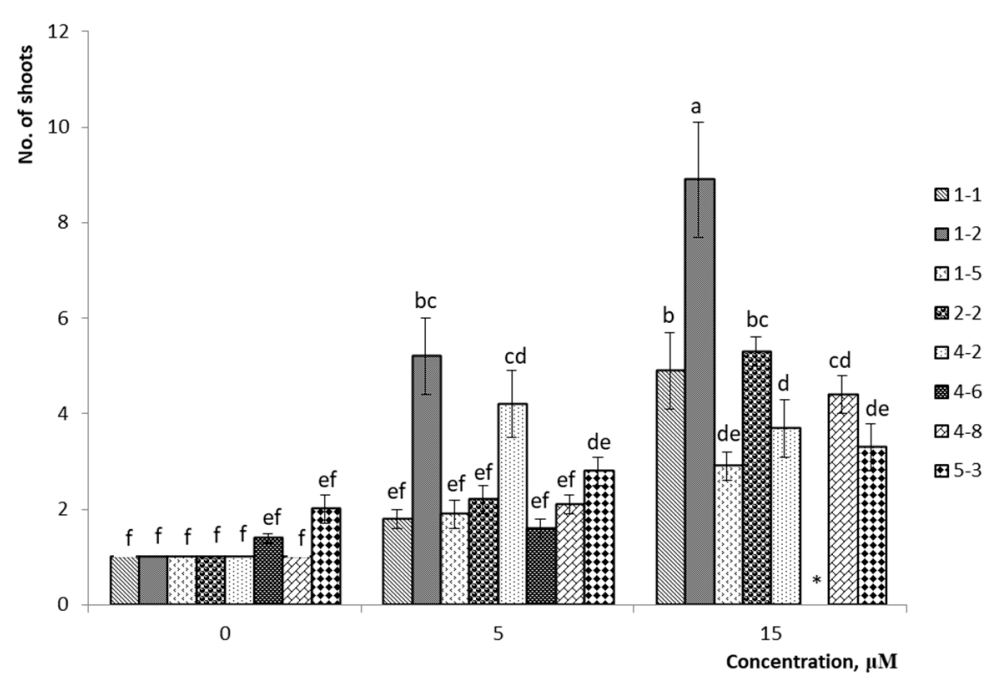

(A)

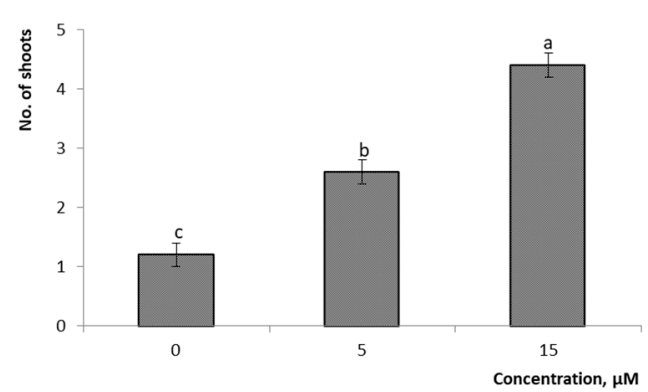

(B)

Figure 4. Effect of $2 \mathrm{iP}$ concentration on the multiplication rate of V.ul.8 $\times{ }^{\prime} \mathrm{NC}$ ': (A) detailed analysis of values of hybrid variants; (B) average values of hybrid variants. Means followed by the same letter are not significantly different according to the LSD at $p \leq 0.05$. Note: *-conglomerate of shoots variant No. 4-6; 1-1, 1-2, 1-5, 2-2, 4-2, 4-6, 4-8, 5-3-variant Nos. 1-1, $1-2,1-5,2-2,4-2,4-6,4-8,5-3$.

The mean shoot height of the studied hybrids significantly decreased as the 2iP concentration increased in the nutrient medium (Figures 6 and $7, p \leq 0.05$ ). Variant Nos. $4-2,4-8$, and 5-3 of the V.ul.8 $\times{ }^{\prime} \mathrm{NC}^{\prime}$ hybrids had no notable differences between the experimental and the control groups. In the nutrient medium lacking growth regulators, 
variant Nos. 1-1, 1-2, 1-5, and 2-2 had the highest shoot heights of 72.4, 72.2, 73.4, and $71.4 \mathrm{~mm}$, respectively. A detailed analysis of the shoot height parameter in hybrid variants showed that all variants of the hybrid of V.ul.8 × 'SC 5-8' had significant differences in only the media with $15 \mu \mathrm{M}$ 2iP. The highest height was observed for variant No. 6-2 when using nutrition without growth regulators, reaching $43.7 \mathrm{~mm}$. The factor analysis confirmed that the shoot height of the studied hybrids was influenced by both 2iP concentration and variants of hybrids $(p \leq 0.05)$. It should be noted that the combination of factors (concentration $\times$ variant) did not significantly affect the height of shoots of V.ul.8 $\times$ 'SC $5-8^{\prime}$ at $p \leq 0.05$ (Table 2).

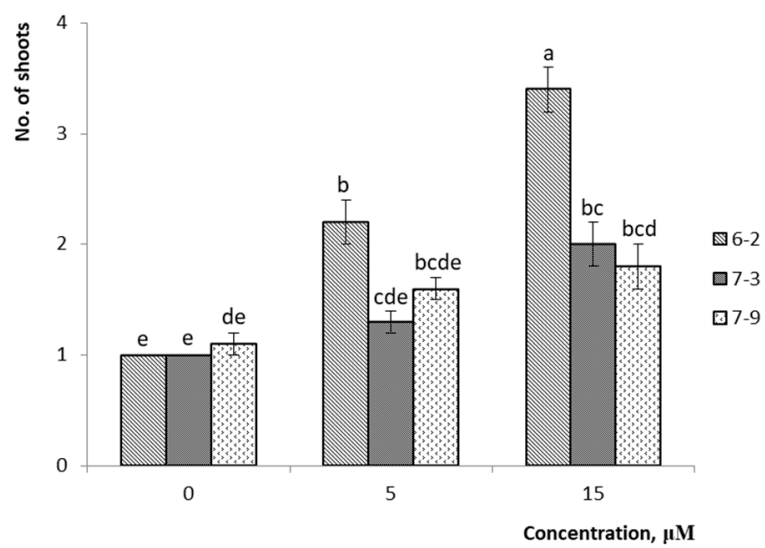

(A)

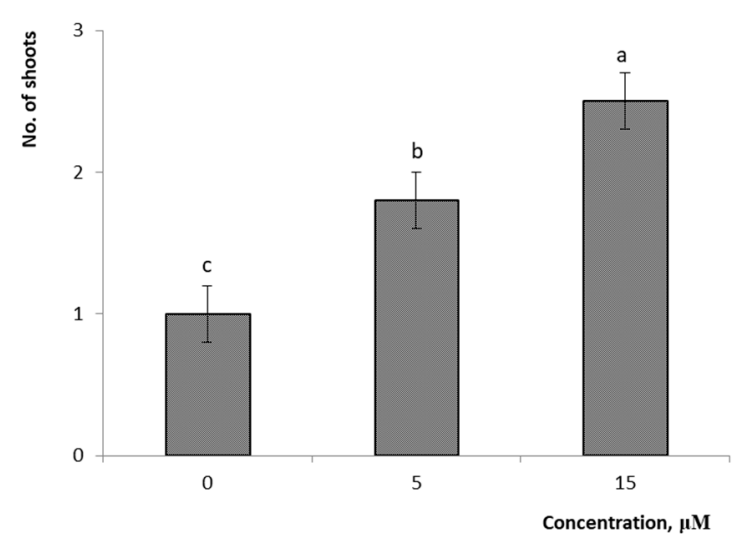

(B)

Figure 5. Effect of 2iP concentration on the multiplication rate of V.ul.8 x 'SC 5-8': (A) detailed analysis of values of hybrid variants; (B) average values of hybrid variants. Means followed by the same letter are not significantly different according to the LSD at $p \leq 0.05$. Note: 6-2, 7-3, 7-9-variant Nos. 6-2, 7-3, 7-9.

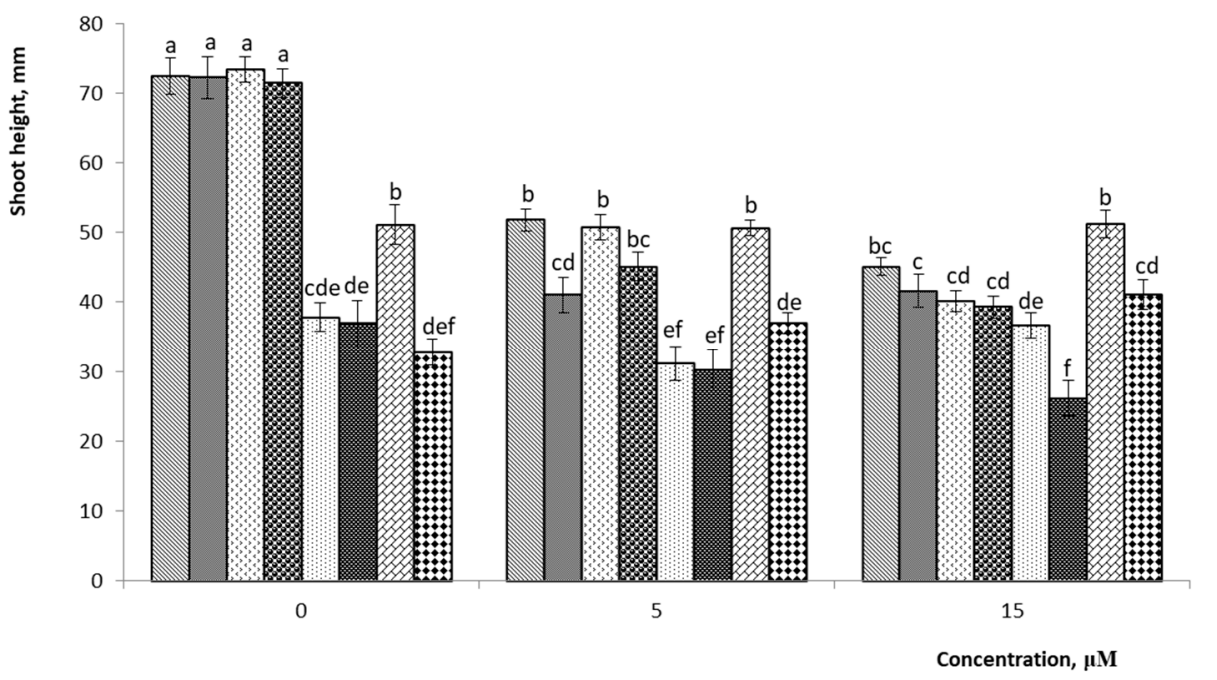

(A)

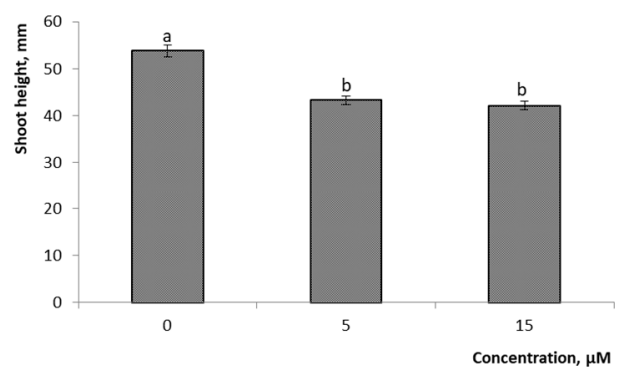

(B)

Figure 6. Effect of 2iP concentration on shoot height of V.ul.8 $\times$ 'NC': (A) detailed analysis of values of hybrid variants; (B) average values of hybrid variants. Means followed by the same letter are not significantly different according to the LSD at $p \leq 0.05$. Note: 1-1, 1-2, 1-5, 2-2, 4-2, 4-6, 4-8, 5-3-variant Nos. 1-1, 1-2, 1-5, 2-2, 4-2, 4-6, 4-8, 5-3.

The results demonstrate the efficiency of using growth regulator-free $1 / 2$ Anderson medium at the rooting stage. Applying this medium made it possible to obtain 100\% rooting for all studied hybrid variants (Figure 1D-J). Plant acclimatization in Sphagnum moss proved to be effective as well whereby it was possible to obtain $90 \%$ viable plants 
for the hybrid of V.ul.8 $\times$ 'NC' and $87 \%$ for V.ul.8 $\times$ 'SC 5-8'. Subsequent planting in the greenhouse and then in the introduction site showed that not all variants had high viability. Some of the hybrid variants died and were dropped from our experiments, indirectly indicating the heterogeneity of the obtained material. After two years of cultivation, we evaluated the growth parameters of the obtained hybrids (Table 3 and Figure 8).

Table 2. Effect of variant features and concentration of $2 \mathrm{iP}$ on the growth and development of $V$. uliginosum $\times(V$. corymbosum $\times V$. angustifolium) hybrids in in vitro culture (ANOVA).

\begin{tabular}{lcccc}
\hline \multirow{2}{*}{ Effect } & \multicolumn{2}{c}{ V.ul.8 $\times{ }^{\prime} \mathrm{NC}^{\prime}$} & \multicolumn{2}{c}{ V.ul.8 $\times$ 'SC 5-8' $^{\prime}$} \\
\cline { 2 - 5 } & Shoot Height & No. of Shoots & Shoot Height & No. of Shoots \\
\hline Concentration & $*$ & $*$ & $*$ & $*$ \\
Variant & $*$ & $*$ & $*$ & $*$ \\
Concentration $\times$ variant & $*$ & $*$ & ns & $*$ \\
\hline
\end{tabular}

Note: *-significant at $p \leq 0.05 ;$ ns—not significant.

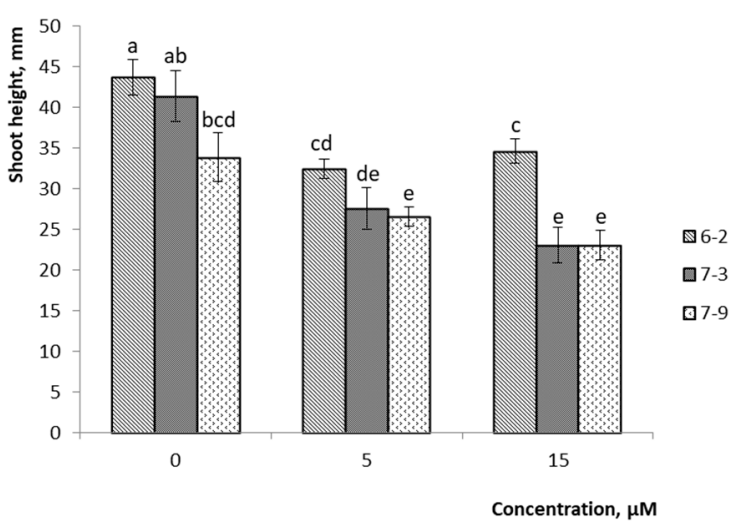

(A)

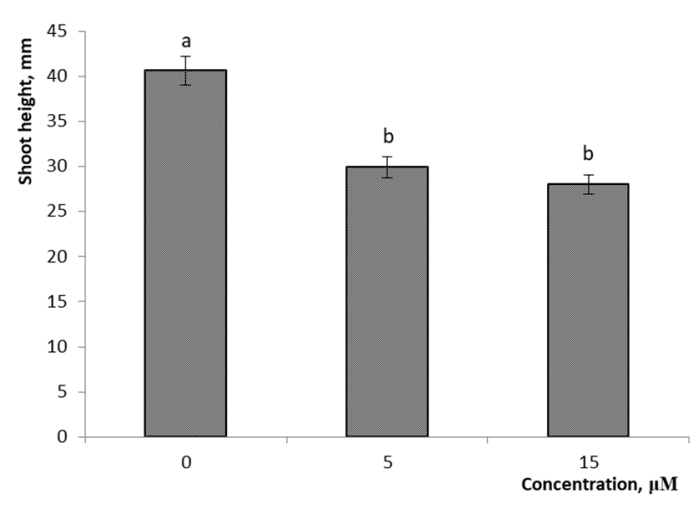

(B)

Figure 7. Effect of 2iP concentration on shoot height of V.ul.8 × 'SC 5-8': (A) detailed analysis of values of hybrid variants; (B) average values of hybrid variants. Means followed by the same letter are not significantly different according to the LSD at $p \leq 0.05$. Note: 6-2, 7-3, 7-9-variant Nos. 6-2, 7-3, 7-9.

Table 3. Growth parameters of $V$. uliginosum $\times(V$. corymbosum $\times V$. angustifolium $)$ hybrids after 2 years of cultivation.

\begin{tabular}{|c|c|c|c|c|}
\hline Variant & Plant Height, mm & Leaf Area, mm ${ }^{2}$ & Leaf Length, mm & Leaf Elongation Coefficient \\
\hline \multicolumn{5}{|c|}{ V.ul. $8 \times{ }^{\prime} \mathrm{NC}^{\prime}$} \\
\hline No. $1-1$ & $79.1 \pm 13.3^{d}$ & $49.8 \pm 7.3^{\mathrm{d}}$ & $9.7 \pm 0.7^{\mathrm{e}}$ & $0.67 \pm 0.05^{\mathrm{a}}$ \\
\hline No. $1-2$ & $156.2 \pm 13.4^{\mathrm{c}}$ & $85.2 \pm 17.8^{\mathrm{d}}$ & $15.2 \pm 1.9^{\mathrm{d}}$ & $0.52 \pm 0.03^{c}$ \\
\hline No. $1-5$ & $250.0 \pm 43.0^{\mathrm{a}}$ & $344.1 \pm 48.9^{\mathrm{a}}$ & $32.2 \pm 2.2^{\mathrm{a}}$ & $0.49 \pm 0.04^{\mathrm{c}}$ \\
\hline No. $2-2$ & $191.5 \pm 44.2^{b}$ & $244.0 \pm 57.1^{b}$ & $22.4 \pm 2.8^{\mathrm{c}}$ & $0.65 \pm 0.05^{\mathrm{ab}}$ \\
\hline No. 4-2 & $124.1 \pm 19.5^{\mathrm{c}}$ & $133.1 \pm 13.8^{\mathrm{c}}$ & $18.5 \pm 1.0^{\mathrm{d}}$ & $0.63 \pm 0.05^{b}$ \\
\hline No. 4-8 & $227.2 \pm 47.9^{a}$ & $260.9 \pm 57.9^{b}$ & $26.5 \pm 3.3^{b}$ & $0.52 \pm 0.02^{c}$ \\
\hline \multicolumn{5}{|c|}{ V.ul. $8 \times$ 'SC $5-8$ ' } \\
\hline No. 7-9 & $190.3 \pm 20.7^{b}$ & $227.4 \pm 47.1^{\mathrm{b}}$ & $25.4 \pm 2.2^{b}$ & $0.52 \pm 0.02^{\mathrm{c}}$ \\
\hline
\end{tabular}

Note: means followed by the same letter are not significantly different according to the LSD at $p \leq 0.05$.

Variant No. 1-5 differed in the highest shoot height and leaf area as well as in having a more elongated leaf blade shape. Variant No. 1-1 differed in its small size and compact shape with more rounded leaves. It should be noted that we did not trace the regularity among the plant heights in in vitro and ex vitro culture. For example, in in vitro culture, variant No. 1-1 did not differ from variant No. 1-5 in terms of height.

The hybrid origin of the obtained samples was confirmed using the ISSR technique with two primers (UBC825 and UBC811) (Figure 9). Fragments in the range of 250-1000 
base pairs of nucleotides were amplified with the UBC825 marker and in the range of 300-900 bp with the UBC811 marker. Both markers distinguished parental genotypes well. Samples 10 and 11 (Figure 9) of $V$. uliginosum were clones of the same form of $V$. uliginosum No. 8, so they generated identical amplicon spectra for each marker with both ISSR markers. All analyzed hybrids inherited DNA fragments of parent plants in various combinations, which confirmed their hybrid nature.
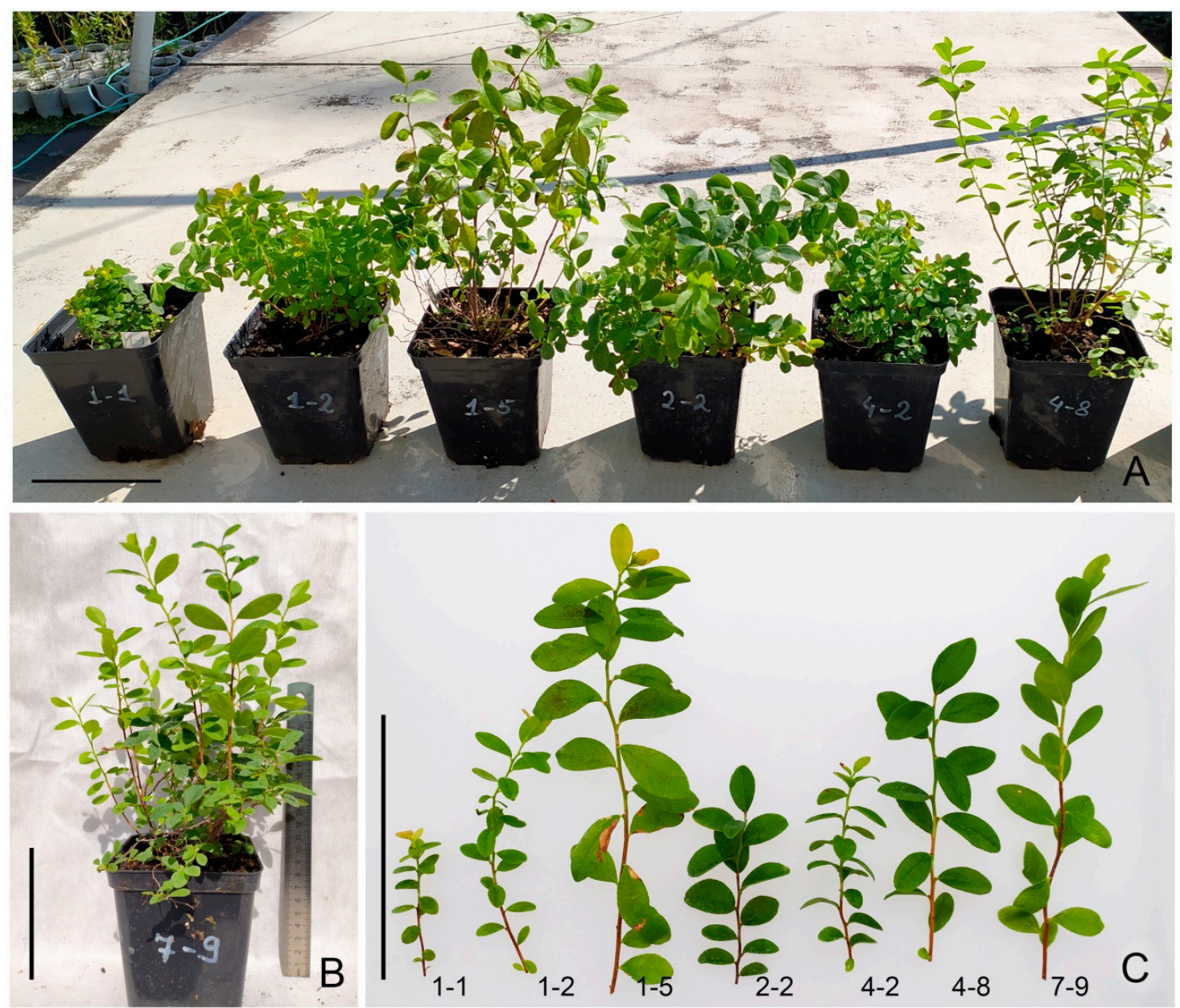

Figure 8. V. uliginosum $\times($ V. corymbosum $\times$ V. angustifolium $)$ hybrids after 2 years of cultivation: (A) V.ul.8 $\times$ 'NC' No. 1-1, 1-2, 1-5, 2-2, 4-2, 4-8; (B) V.ul.8 × 'SC 5-8' No. 7-9; (C) annual shoots of No. 1-1, 1-2, 1-5, 2-2, 4-2, 4-8, 7-9. Bar: 10 cm.

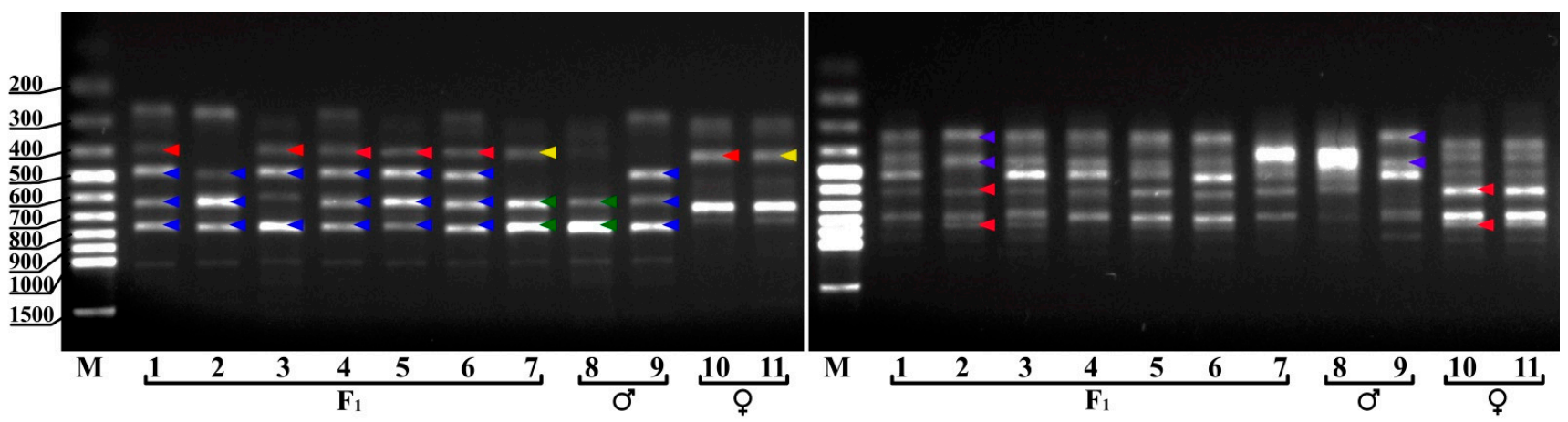

Figure 9. ISSR-PCR eletrophoregrams of genomic DNA with primers UBC825 (left) and UBC811 (right). 1-6-V.ul.8 $\times$ 'NC' No. 1-1, No. 1-2, No. 1-5, No. 2-2, No. 4-2, No. 4-8; 7-V.ul.8 × 'SC 5-8' No. 7-9; 8-'SC 5-8 (o'1)'; 9 -’NC' (o’2); $10-V . u l .8$ (क1), 11-V. ul. 8 (क2). Note: red arrows—o1-specific markers; yellow arrows— +2 -specific markers; green arrows—o 1 -specific markers; blue arrows-o 2 -specific markers. 


\section{Discussion}

According to our data, the germination rate was $80 \%$ when sowing seeds of similar hybrid combinations into a soil substrate, but only a few specimens were viable (no more than $2 \%$ ). In in vitro culture, seed germination was comparable, but the survival rate was $78.6 \%$ for the hybrid of V.ul.8 $\times$ 'NC', while it was $31.8 \%$ for V.ul.8 $\times$ 'SC 5-8' hybrid. In vitro technologies made it possible to overcome the negative effect of various factors on seed germination and seedling viability at the initial stages of development, thus allowing the preservation of unique genetic material. Pathirana et al. [1] showed that in vitro cultivation of embryoids allowed postzygotic barriers to be overcome during interspecific hybridization of Vaccinium species with different ploidy levels. In addition, treatment with colchicine allowed viable amphiploids of $V$. corymbosum $\times V$. ashei hybrids to be obtained in in vitro culture [2].

The choice of nutrient media was based on the fact that the mother plant of the obtained hybrids was $V$. uliginosum. Although there are a number of reports of in vitro propagation of Vaccinium representatives [11-16], only a few are devoted to V. uliginosum micropropagation. Cüce et al. [17] showed that V. uliginosum plants (populations from Trabzon, Turkey) were successfully propagated in vitro on Woody Plant medium (WPM) supplemented with $1.0 \mathrm{mg} / \mathrm{L}$ zeatin and $0.1 \mathrm{mg} / \mathrm{L} \beta$-indolebutyric acid (IBA). The multiplication rate was $3.46 \pm 0.59$ shoots/explant, and the shoot height was $34.98 \pm 1.51 \mathrm{~mm}$. Zong et al. [18] successfully propagated V. uliginosum (populations from Changbai Mountain, China) on Murashige and Skoog medium (MS) with the addition of $0.5 \mathrm{mg} / \mathrm{L}$ zeatin and $0.2 \mathrm{mg} / \mathrm{L}$ IBA (multiplication rate of 5.3 shoots/explant). Gu et al. [19] noted that successful shoot regeneration was achieved on Debnath and McRae medium supplemented with $2.75 \mathrm{mg} / \mathrm{L} 2 \mathrm{iP}$ and $0.10 \mathrm{mg} / \mathrm{L} \alpha$-indoleacetic acid (IAA). Weng et al. [20] developed an in vitro propagation system for $V$. uliginosum $\mathrm{cv}$. Zishuijing. The optimal medium was WPM supplemented with 6-benzyladenine (6-BA) $1 \mathrm{mg} / \mathrm{L}$ and zeatin $1 \mathrm{mg} / \mathrm{L}$. We previously showed that for the propagation of four varieties of $V$. uliginosum, two-stage cultivation is optimal: 2 weeks on Anderson's nutrient medium supplemented with $20 \mu \mathrm{M} 2 \mathrm{iP}$, and then on the same medium with $5 \mu \mathrm{M}$ 2iP. The multiplication rate was from six to seventeen shoots/explant, depending on the variety, and the shoot height was 30-35 $\mathrm{mm}$ [21-23].

Our study showed that the maximum reproduction factor of the studied hybrids was obtained on Anderson nutrient medium with $15 \mu \mathrm{M}$ 2iP, producing 8.9 shoots/explant for variant No. 1-2 of the V.ul.8 $\times$ ' $\mathrm{NC}^{\prime}$, and 3.4 shoots/explant for variant No. 6-2 of V.ul.8 $\times$ 'SC 5-8'. Generally, the hybrid of V.ul.8 $\times$ 'NC' had greater shoot height for all tested variants of nutrient media compared with V.ul.8 $\times$ 'SC 5-8'. The greatest height of $43.7 \mathrm{~mm}$ occurred for the hybrid shoots on a nutrient medium without growth regulators for variant No. 6-2 of V.ul.8 × 'SC 5-8', while the heights of variant Nos. 1-1, 1-2, 1-5, and 2-2 of V.ul.8 $\times$ ' $\mathrm{NC}^{\prime}$ were $72.4,72.2,73.4$, and $71.4 \mathrm{~mm}$, respectively. Our data indicate that the hybrid variant of $V$. uliginosum $\times(V$. corymbosum $\times V$. angustifolium $)$ considerably affected the growth and development indices, which should be considered to optimize nutrient media and cultivation conditions further. At the same time, there were data showing the reverse trend. It was demonstrated that the growth medium-and not the genotype and physical conditions of cultivation - primarily affected the shoot height and multiplication coefficient of five genotypes of the genus Vaccinium spp. [24].

We previously observed that $V$. uliginosum varieties are characterized by different rooting abilities in in vitro culture [25]. Some varieties demonstrated $100 \%$ rooting on hormone-free media, while others required preliminary treatment with auxins. The hybrids studied were characterized by $100 \%$ rooting on $1 / 2$ A hormone-free nutrient medium.

Our results confirmed that ISSR markers are efficient tools for the discrimination of F1 hybrids of $V$. uliginosum $\times(V$. corymbosum $\times V$. angustifolium $)$ in controlled crosses. In addition, ISSR markers allow for the easy, fast, inexpensive, accurate, reliable, and simultaneous detection of polymorphisms at multiple loci in the genome using low quantities of DNA. These properties make the markers useful for the genetic analysis of various plants. ISSRs are found to be effective in diversity analyses of lowbush blueberry [25] and 
lingonberry [26]. To the best of our knowledge, this research is the first to use ISSR markers for hybrid verification in $V$. uliginosum $\times(V$. corymbosum $\times V$. angustifolium $)$.

\section{Materials and Methods}

The experimental scheme is shown in Figure 2.

\subsection{Plant Material}

Seven samples of seeds from three-species hybrids were placed in in vitro culture: 2 samples of V.ul.8 × 'SC 5-8', and 5 samples of V.ul.8 $\times$ 'NC', obtained in 2017 at an experimental site of the Laboratory for Food Plant Introduction of the Central Siberian Botanical Garden of the Siberian Branch of the Russian Academy of Sciences (CSBG SB RAS) (Novosibirsk, Russia). Each hybrid variant (seedling) was given an ordinal number (Table 1). The original parent plants of V. uliginosum were collected in 2003 in the Kolyvan' district of Novosibirsk region (the upper reaches of the Shegarka river), and studied at the CSBG SB RAS' experimental site. The origins of the paternal forms are as follows: 'Northcountry' is an interspecific hybrid of $V$. corymbosum (B6) $\times(V$. corymbosum $\times V$. angustifolium) (R2P4) obtained in Minnesota, USA, in 1973; SC 5-8 is a spontaneous hybrid of $V$. corymbosum $\times V$. angustifolium, from which seeds were collected by T. Paal on Prince Edward Island, Canada, the seedlings were grown in the vicinity of Tartu city (Estonia), and were transferred to CSBG SB RAS in 2006.

\subsection{In Vitro Propagation of Interspecific Hybrids}

Seeds were surface sterilized with $20 \%$ Domestos solution for $20 \mathrm{~min}$, followed by three times rinsing in sterile distilled water. Seeds were germinated on $0.6 \%$ water agar at $24 \pm 1{ }^{\circ} \mathrm{C}$ under a $16 / 8 \mathrm{~h}$ photoperiod with lighting of $54 \mu \mathrm{mol} \mathrm{m}{ }^{-2} \mathrm{~s}^{-1}$. After 30 days of cultivation, the seedlings were placed on Anderson nutrient medium [27] supplemented with $5 \mu \mathrm{M}$ 2iP (Sigma-Aldrich, St Louise, MI, USA), 3\% sucrose, and 0.5\% agar. Seedlings at the second passage were cut into single-node segments and cultured on the same nutrient medium for another 60 days. Then, the microshoots were transplanted twice and cultivated on the same medium with 40 days interval. To assess the effect of cytokinin P on shoot formation, 5 and $15 \mu \mathrm{M} 2 \mathrm{iP}$ were used at the fifth passage. Growth regulator-free Anderson medium was used as a control. The microshoots obtained at the stage of multiplication were cut and planted for rooting on half strength growth regulator-free Anderson medium (1/2 Anderson medium). All nutrient media were adjusted to $\mathrm{pH} 5.7$ with $\mathrm{KOH}$ before autoclaving.

\subsection{Acclimatization of Regenerated Plants}

Healthy plants with well-developed shoots and roots were removed individually from the culture vessels, washed gently under running tap water and transferred to plastic pots containing Sphagnum moss at $24 \pm 1{ }^{\circ} \mathrm{C}$ under a $16 / 8 \mathrm{~h}$ photoperiod with lighting of $54 \mu \mathrm{mol} \mathrm{m} \mathrm{m}^{-2} \mathrm{~s}^{-1}$ for 1.5 months. A high relative humidity (above 80\%) was maintained for the first 14 days. The acclimatized plants were planted in a greenhouse in plastic seedling trays with a substrate containing neutral and acidic peat in a 2:1 ratio for further 4 weeks and, finally, they were transferred to the nursery.

\subsection{DNA Isolation and ISSR Analysis}

DNA was isolated of fresh leaves using a modified CTAB method [28]. Polymerase chain reaction (PCR) was performed on a C-1000 amplifier (Bio-Rad, Hercules, CA, USA) in $15 \mu \mathrm{L}$ volume. The standard reaction contained a single Taq buffer, a mixture of $0.2 \mathrm{mM}$ each dNTP, $2.5 \mathrm{mM}$ free $\mathrm{Mg}^{2+}, 1 \mu \mathrm{M}$ ISSR primer, $1.5 \mathrm{ng} / \mu \mathrm{L}$ total DNA, a unit of HS Taq DNA polymerase (Eurogen, Russia). The amplification was carried out as follows: predenaturation at $94^{\circ} \mathrm{C}-4 \mathrm{~min} ; 38$ cycles denaturation at $94^{\circ} \mathrm{C}-25 \mathrm{~s}$, annealing at $60^{\circ} \mathrm{C}-$ $30 \mathrm{~s}$, elongation at $72{ }^{\circ} \mathrm{C}-2 \mathrm{~min}$; final elongation $-10 \mathrm{~min}$ at $72{ }^{\circ} \mathrm{C}$, and storage at $4{ }^{\circ} \mathrm{C}$ until further use. PCR aliquot containing the amplified fragment was stained with SYBR Green 
I, and analyzed by electrophoresis in $1.7 \%$ agarose gel using $1 \times$ TAE buffer at $4 \mathrm{~V} \mathrm{~cm}^{-1}$ voltage. ISSR markers (Eurogen, Russia) were used: UBC825 (Sequence $\left(5^{\prime}-3^{\prime}\right):(\mathrm{AC})_{8} \mathrm{~T}, \mathrm{Tm}$ : $60{ }^{\circ} \mathrm{C}$ ), UBC811 (Sequence $\left(5^{\prime}-3^{\prime}\right)$ : $(\mathrm{GA})_{8} \mathrm{C}, \mathrm{Tm}: 60^{\circ} \mathrm{C}$ ). The sizes of the PCR products were compared with the molecular size standard 100+ bp DNA ladder (Eurogen, Russia).

\subsection{Data Analysis}

Measurements were replicated twice using 100 microshoots per experiment. Statistical analysis was carried out in Statistica 6.0 (LSD-test, ANOVA, $p \leq 0.05$ ) (StatSoft Inc., Tulsa, $\mathrm{OK}, \mathrm{USA})$. Data are presented as mean and standard errors $(\mathrm{M} \pm \mathrm{SE})$. To study the different quality plants and leaves, the following indicators were taken into account: plant height $(\mathrm{mm})$, leaf length $(\mathrm{mm})$, leaf area $\left(\mathrm{mm}^{2}\right)$, leaf elongation coefficient. The processing of images of seeds was carried out using the SIAMS Photolab system for obtaining and processing images (Siams, Russia).

\section{Conclusions}

Thus, the study revealed that the survival rate of seedlings of $V$. uliginosum $\times(V$. corymbosum $\times V$. angustifolium) hybrids in in vitro culture greatly exceeded their viability in a soil substrate. Genotypic differences in the multiplication rate and shoot height among the studied hybrid variants were identified. We showed that the maximum multiplication rate was achieved when using Anderson nutrient medium containing $15 \mu \mathrm{M} 2 \mathrm{iP}$. The factor analysis confirmed that both the 2iP concentration and the variant of hybrid influenced the multiplication rate and shoot height of the studied hybrids. The efficiency of using $1 / 2 \mathrm{~A}$ hormone-free nutrient medium was evident at the stage of rooting. We did not find any regularities between plant heights in in vitro and ex vitro culture. ISSR demonstrated that all analyzed hybrids inherited DNA fragments of the parent plants in various combinations, which confirmed their hybrid nature. Thus, this study demonstrates that applying in vitro methods for the propagation and further selection of genotypes is an effective approach in programs to obtain interspecific hybrids of $V$. uliginosum $\times(V$. corymbosum $\times V$. angustifolium). These hybrids may be useful as breeding material for creating new high-quality varieties in the future.

Author Contributions: Designed the experiment, analyzed the results, and prepared the manuscript, A.A.E., A.B.G. and S.V.A.; performed the experiments and analyzed the results, A.S.E.; writingreview and editing, E.V.B.; project administration, E.V.B. and M.A.T. All authors have read and agreed to the published version of the manuscript.

Funding: This research was funded by budgetary project No. AAAA-A21-121011290027-6 of the Central Siberian Botanical Garden of the Siberian Branch of the Russian Academy of Sciences (CSBG SB RAS), Novosibirsk, Russia.

Institutional Review Board Statement: Not applicable.

Informed Consent Statement: Not applicable.

Data Availability Statement: Data available on request due to restriction.

Acknowledgments: To prepare the publication, materials of the bioresource scientific collection of the Central Siberian Botanical Garden of the SB RAS "Collection of living plants indoors and outdoors", USU_440534 were used. The author appreciates T.I. Snakina, a researcher of the Laboratory for Food Plant Introduction of CSBG SB RAS, for his assistance in the experiment (hybridization).

Conflicts of Interest: The authors declare no conflict of interest.

\section{References}

1. Pathirana, R.; Wiedow, C.; Pathirana, S.; Hedderley, D.; Morgan, E.; Scalzo, J.; Frew, T.; Timmerman-Vaughan, G. Ovule culture and embryo rescue facilitate interspecific hybridisation in blueberry (Vaccinium spp.). Acta Hortic. 2015, 1083, 123-132. [CrossRef]

2. Miyashita, C.; Ishikawa, S.; Mii, M. In vitro induction of the amphiploid in interspecific hybrid of blueberry (Vaccinium corymbosum $\times$ Vaccinium ashei) with colchicine treatment. Sci. Hortic. 2009, 122, 375-379. [CrossRef]

3. Rousi, A. Hybridization between Vaccinium uliginosum cultivated blueberry. Ann. Agric. Fenn. 1963, 2, 12-18. 
4. Czesnik, E. Investigation of F1 generation of interspecific hybrids Vaccinium corymbosum L. $\times$ Vaccinium uliginosum L. Acta Hortic. 1985, 165, 85-92. [CrossRef]

5. Czesnik, E.; Madry, W. Inheritance of some characters of the F1 generation of interspecific hybrids Vaccinium corymbosum L. $\times$ Vaccinium uliginosum L. Acta Hortic. 1989, 241, 50-55. [CrossRef]

6. Gorbunov, A.B. Introduction and selection of lingonberry plants in the CSBG. State Probl. Gard. Russ. 1997, 1, 312-316.

7. Shigyou, M.; Gushiken, A.; Katsuragawa, A.; Hiji, M.; Yoshioka, K.; Kage, T.; Kunitake, H.; Komatsu, H. Evaluation of F1 progenies derived from intersectional crossing of Vaccinium uliginosum L., a wild species native to Japan, and highbush blueberry 'Bluecrop' (V. corymbosum L.). Hortic. Res. 2014, 13, 97-106. [CrossRef]

8. Luzyanina, O.V. Reproductive Biology of Vacciniaceae Promising for Introduction and Breeding in Siberia. Ph.D. Dissertation, CSBG SB RAS, Novosibirsk, Russia, 2002.

9. Gorbunov, A.B. Introduction and breeding of Vaccinium and Oxycoccus species in Siberia. J. Small Fruit Vitic. 1992, 1, 55-66. [CrossRef]

10. Munoz, C.E.; Lyrene, P.M. In vitro attempts to overcome the cross-incompatibility between Vaccinium corymbosum L. and V. elliottii Chapm. Theor. Appl. Genet. 1985, 69, 591-596. [CrossRef] [PubMed]

11. Debnath, S.C. Propagation of Vaccinium in vitro. Int. J. Fruit Sci. 2007, 6, 47-71. [CrossRef]

12. Meiners, J.; Schwab, M.; Szankowski, I. Efficient in vitro regeneration systems for Vaccinium species. Plant. Cell Tissue Organ. Cult. 2007, 89, 169-176. [CrossRef]

13. Tetsumura, T.; Matsumoto, Y.; Sato, M.; Honsho, C.; Yamashita, K.; Komatsu, H.; Sugimoto, Y.; Kunitake, H. Evaluation of basal media for micropropagation of four highbush blueberry cultivars. Sci. Hortic.-Amst. 2007, 119, 72-74. [CrossRef]

14. Ruzic, D.; Vujovic, T.; Libiakova, G.; Cerovic, R.; Gajdosova, A. Micropropagation in vitro of highbush blueberry (Vaccinium corymbosum L.). J. Berry Res. 2012, 2, 97-103. [CrossRef]

15. Bakhshipour, M.; Mafakheri, M.; Kordrostami, M.; Zakir, A.; Rahimi, N.; Feizi, F.; Mohseni, M. In vitro multiplication, genetic fidelity and phytochemical potentials of Vaccinium arctostaphylos L.: An endangered medicinal plant. Ind. Crop. Prod. 2019, 141, 111812. [CrossRef]

16. Debnath, S.C.; Goyali, J.C. In vitro propagation and variation of antioxidant properties in micropropagated Vaccinium berry plants-A review. Molecules 2020, 25, 788. [CrossRef] [PubMed]

17. Cüce, M.; Bekİrcan, T.; Sökmen, A. Phenolic constituents of Vaccinium species from both natural resources and micropropagated plantlets. Int. J. Second. Metab. 2018, 5, 304-311. [CrossRef]

18. Zong, C.L.; Zong, C.W.; Zhao, W.W.; Jin, B.K.; Cao, H.N. In vitro culture of superior individual of Vaccinium uliginosum from Changbai Mountain. North. Hortic. 2012, 4, 043.

19. Gu, D.Z.; Gao, H.D.; Gu, M.Y.; Zhu, J.Y.; Jiang, Y.T. In vitro culture and plant regeneration system of Vaccinium uliginosum. For. Res. 2009, 22, 226-229.

20. Weng, H.; Tian, X.; Shi, D. Key technology of in-vitro culture for a new Vaccinium uliginosum cultivar Zishuijing. Agric. Sci. Technol. 2015, 16, 1172-1176+1203.

21. Vechernina, N.A.; Tavartkiladze, O.C.; Gorbunov, A.B.; Erst, A.A. Propagation in vitro of bog bilberry. Vestn. Altai State Agrar. Univ. 2008, 6, 21-25.

22. Erst, A.A.; Vechernina, N.A. Micropropagation of promising new cultivars of Vaccinium uliginosum L. Bull. Kharkov Natl. Agrar. Univ. Biol. Ser. 2010, 2, 96-103.

23. Erst, A.A.; Gorbunov, A.B.; Erst, A.S. Effect of concentration, method of auxin application and cultivation conditions on in vitro rooting of bog blueberry (Vaccinium uliginosum L.). J. Berry Res. 2018, 8, 41-53. [CrossRef]

24. Scalzo, J.; Donno, D.; Miller, S.; Ghezzi, M.; Mellano, M.G.; Cerutti, A.K.; Beccaro, G.L. Effect of genotype, medium and light on in vitro plant proliferation of Vaccinium spp. N. Z. J. Crop Hortic. Sci. 2016, 44, 231-246. [CrossRef]

25. Debnath, S.C. Development of ISSR markers for genetic diversity studies in Vaccinium angustifolium. Nord. J. Bot. 2009, 27, 141-148. [CrossRef]

26. Debnath, S.C. Inter simple sequence repeats (ISSR) to assess genetic diversity within a collection of wild lingon-berry (Vaccinium vitisidaea L.) clones. Can. J. Plant Sci. 2007, 87, 337-344. [CrossRef]

27. Anderson, W.C. Propagation of rhododendrons by tissue culture. I. Development of a culture medium for multiplication of shoots. Comb. Proc. Int. Plant Propagator. Soc. 1975, 25, 129-133.

28. Khanuja, S.P.; Shasany, A.K.; Darokar, M.; Kumar, S. Rapid isolation of DNA from dry and fresh samples of plants producing large amounts of secondary metabolites and essential oils. Plant Mol. Biol. Rep. 1999, 17, 74. [CrossRef] 